\title{
Loss of Range of Motion
}

National Cancer Institute

\section{Source}

National Cancer Institute. Loss of Range of Motion. NCI Thesaurus. Code C50637.

A finding that the flexibility of a joint is below the expected range of normal for that individual. 